\title{
Survey protocol for detecting chytridiomycosis in all Australian frog populations
}

\author{
Lee F. Skerratt ${ }^{1, *}$, Lee Berger ${ }^{1}$, Harry B. Hines ${ }^{2}$, Keith R. McDonald ${ }^{3}$, \\ Diana Mendez ${ }^{1}$, Richard Speare ${ }^{1}$ \\ ${ }^{1}$ Amphibian Disease Ecology Group, School of Public Health, Tropical Medicine and Rehabilitation Sciences, \\ James Cook University, Townsville, Queensland 4811, Australia \\ ${ }^{2}$ Queensland Parks and Wildlife Service, PO Box 64, Bellbowrie, Queensland 4070, Australia \\ ${ }^{3}$ Amphibian Disease Ecology Group, Queensland Parks and Wildlife Service, PO Box 975, Atherton, Queensland 4883, Australia
}

\begin{abstract}
Spread of the amphibian chytrid fungus Batrachochytrium dendrobatidis $(B d)$ has caused the decline and extinction of frogs, but the distribution of $B d$ is not completely known. This information is crucial to implementing appropriate quarantine strategies, preparing for outbreaks of chytridiomycosis due to introduction of $B d$, and for directing conservation actions towards affected species. This survey protocol provides a simple and standard method for sampling all frog populations in Australia to maximise the chances of detecting $B d$. In order to structure and prioritise the protocol, areas are divided by bioregion and frog species are allocated depending on the water bodies they utilize into 3 groups representing different levels of risk of exposure to $B d$. Sixty individuals per population need to be tested to achieve $95 \%$ certainty of detecting 1 positive frog, based on the minimum apparent prevalence of $\geq 5 \%$ in infected Australian frog populations and using a quantitative real-time TaqMan PCR test. The appropriate season to sample varies among bioregions and will ideally incorporate temperatures favourable for chytridiomycosis (e.g. maximum air temperatures generally $<27^{\circ} \mathrm{C}$ ). Opportunistic collection and testing of sick frogs and tadpoles with abnormal mouthparts should also be done to increase the probability of detecting $B d$. The survey priorities in order are (1) threatened species that may have been exposed to $B d_{1}$ (2) bioregions surrounding infected bioregions/ecological groups, and (3) species of frogs of unknown infection status in infected bioregions. Within these priority groups, sampling should first target ecological groups and species likely to be exposed to $B d$, such as those associated with permanent water, and areas within bioregions that have high risk for $B d$ as indicated by climatic modelling. This protocol can be adapted for use in other countries and a standard protocol will enable comparison among amphibian populations globally.
\end{abstract}

KEY WORDS: Batrachochytrium dendrobatidis $\cdot$ Mapping $\cdot$ Chytrid fungus · Disease $\cdot$ Decline $\cdot$ Amphibian

\section{INTRODUCTION}

The amphibian disease chytridiomycosis, caused by the fungus Batrachochytrium dendrobatidis $(B d)$, invaded Australia, probably in the 1970s (Berger et al. 1999). Infection with the amphibian chytrid fungus, resulting in chytridiomycosis, is a 'Key Threatening Process' for Australian frogs (Australian Government Department of the Environment and Heritage [AGDEH] 2006). This fungus has also caused the decline and extinction of frogs in other countries, but the distribution of $B d$ globally is not completely known (Skerratt et al. 2007, Olson \& Ronnenberg 2008, Berger et al. in press). It occurs in all continents except Antarctica, in a wide range of habitats and climates (Speare \& Berger 2007).

National mapping protocols to identify country-wide distributions of chytridiomycosis have not been published. The background document to the Australian Government Threat Abatement Plan for chytridiomy- 
cosis discusses the issues involved (AGDEH 2006). Scientists have done studies on the prevalence of chytridiomycosis in populations at particular sites, but there have been no systematic studies at a state/province or national scale. Weldon et al. (2004), in their histological study of museum specimens extending back to the 19th century, demonstrated that chytridiomycosis is widespread in southern Africa. Ouellet et al. (2005) performed a similar study on museum specimens from 25 countries but with the major focus on Canadian amphibians. However, both studies were opportunistic and not designed as systematic national surveys. Garner et al. (2005) used PCR to map $B d$ in 13 European countries and reported results only as prevalence by country.

Patchy data on the distribution of $B d$ in Australia exists from opportunistic collection of sick or dead frogs (Berger et al. 2004) and surveys of healthy frogs from restricted locations including examination of archived specimens (McDonald et al. 2005, Speare et al. 2005, Kriger et al. 2007). The fungus has been found on 46 species from 3 families (Hylidae, Myobatrachidae and Bufonidae) in Australia (AGDEH 2006). It has also been reported in 1 individual of Cophixalus ornatus (belonging to the family Microhylidae) (Kriger \& Hero 2006). However, this result needs to be interpreted with caution, as 557 microhylids, including $C$. ornatus, from the areas surrounding the positive record have tested negative for $B d$ by either quantitative real-time PCR (qPCR) or histology (K. Hauselberger \& D. Mendez et al. unpubl. data). Chytridiomycosis is known to occur in eastern Australia from Tasmania north to Cooktown (occurring mainly on or between the Great Dividing Range and the coast), around Adelaide in South Australia, and in southwest Western Australia (Berger et al. 2004, Speare et al. 2005). $B d$ has been found in most areas in Australia where it is predicted to occur based on modelling the climatic variables that described the known distribution of $B d$ in Australia in 2003 (Retallick 2003). Although this model may reflect some collection biases, recent surveys have detected $B d$ in areas where the model predicted a high likelihood of occurrence, such as Tasmania, and have failed to detect it in hot or dry areas where it is unlikely to occur, such as the Northern Territory, Cape York Peninsula, inland arid areas of Queensland, and northwest Western Australia (Speare et al. 2005). Ron (2005) produced a model that is valuable in predicting climatic suitability for $B d$ at a larger spatial scale. The known biology of $B d$ suggests that high temperatures and lack of permanent water bodies are likely to limit its distribution (Johnson et al. 2003, Berger et al. 2004, Piotrowski et al. 2004, Kriger \& Hero 2007a, Kriger et al. 2007). More detailed mapping is important as it will identify the exact limits of the distribution of $B d$, taking the guesswork out of management decisions on quarantine and management of frogs that have been translocated and helping to direct conservation actions towards populations that are most likely to be affected by chytridiomycosis. This data will also improve the accuracy of a model of the biogeographic requirements for $B d$ and help identify naïve populations that would be at risk if $B d$ was introduced.

The aim of this survey protocol is to provide a simple and standard method for sampling all wild frog populations in Australia for infection with $B d$. It also provides priorities for surveillance and justification for extrapolation of results to minimise the number of populations that need to be surveyed. To systematically survey all frog populations throughout Australia is a major task logistically, due to the large land area, the diversity of environments and the large number of amphibian species. Therefore, there is a need to simplify and prioritise the task by splitting the continent into areas and allocating species of frogs into groups that reflect the risk of exposure to $B d$. This will result in more manageable units (both area- and species-wise) to survey initially and enable prioritisation of units to survey. The number of areas and species that need to be surveyed could be reduced if results from comparable areas and species were extrapolated. For example, if species that are susceptible and likely to be exposed to $B d$ are negative then it is likely that other species in the same area are also negative. We discuss these issues and how to prioritise the work, the number of frogs that need to be sampled, the time of year to sample, the life-stage to sample, the sampling strategy to employ, the logistics of sampling, and which diagnostic test should be used. We designed the survey protocol so that it could be used by professional and amateur herpetologists and volunteers working with conservation agencies and other institutions. This protocol could be adapted for surveying amphibian populations in other countries. As the World Organisation for Animal Health moves towards implementation of disease protocols for the international movement of amphibians (OIE 2006), a standard technique that can be used to assess the chytridiomycosis-status of countries and demonstrate adequate surveillance will become essential.

\section{MATERIALS AND METHODS}

Key aspects to consider when surveying. Priorities: The task of surveying all Australian frog populations is large. For many frog species, information on the extent of their distribution patterns is unknown. Therefore, this survey protocol aims to take into account the feasi- 
bility of such an undertaking. Surveys for chytridiomycosis in threatened species/populations in infected bioregions are the initial priority for conservation management. This has mostly been done in eastern Australia and is currently underway in southern Australia. The next priority would be to sample for $B d$ in those frog populations near known infected populations, working outwards incrementally from infected populations. Therefore, unsurveyed bioregions adjacent to bioregions that have chytridiomycosis would be surveyed next. This is because $B d$ spreads naturally and chytridiomycosis has been found within coastal bioregions of Australia, which appear to be the preferred habitat and climate for $B d$, i.e. lower maximum temperatures and higher rainfall (Berger et al. 2004). Moving inland and into hot monsoonal and arid areas, the habitat and climate for chytridiomycosis becomes less preferable; therefore it is less likely to be present. If low-probability areas surrounding infected areas are negative, then we do not recommend additional sampling of areas with similar low probabilities further inland or to the north, in order to reduce costs. This sampling strategy is stratified on the basis of risk of the occurrence of $B d$. However, one must consider humanassisted transport of $B d$ that occurs ahead of a naturally spreading front (Laurance et al. 1996, Berger et al. 1998, Lips et al. 2006). One must also consider that there may be pockets of favourable habitat for $B d$ within inhospitable areas, where human assisted introduction could occur. Surveying ecological groups that have not been sampled previously within infected bioregions is the next highest priority to assist management. The last priority is to sample non-threatened species in infected regions that have not been sampled. This is because these species are likely to have a similar infection status to other species within the same ecological group.

Within the above priorities, surveys in eastern Australia indicate that it is important to initially survey species at high risk of chytridiomycosis. High risk species are permanent stream- and then permanent pondassociated species, especially those that have declined, in mesic environments with air temperatures $<27^{\circ} \mathrm{C}$ for most of the year (Berger et al. 2004, Speare et al. 2005, Kriger \& Hero 2007a).

Area: Australia has a land area of $7617930 \mathrm{~km}^{2}$ (CIA 2007). In order to make sampling feasible, we propose using interim biogeographic regionalisation of Australia as defined by geology, climate and vegetation for our sampling scale, and to prioritise sampling based on likelihood of a region having $B d$ (Department of the Environment, Water, Heritage and the Arts 2008). For large bioregions, such as the Southern and Northern Brigalow Belts, which are $1000 \mathrm{~km}$ in length and cover $25 \%$ of Queensland, it may be necessary to divide the bioregion into smaller sub-regions or areas $200 \mathrm{~km}$ in length, and to prioritise areas to be sampled first (Department of the Environment, Water, Heritage and the Arts 2008).

An important logistic consideration in surveying is ease of access to amphibian populations. This can be the major consideration in remote areas. Typically surveys are done close to road access.

Species: There are approximately 220 free-living frog species in Australia. In order to minimise costs, and target areas and species with a high probability of $B d$, there is a need to group frog species with similar risk of exposure. Because $B d$ is a pathogen mostly associated with aquatic or high rainfall habitats and requires moisture for survival when in the environment (Johnson \& Speare 2003, Johnson et al. 2003), frogs have been grouped according to the type of water body they typically utilize, which is usually dependent on their breeding strategy. We define 3 ecological groups: (1) permanent water group, aquatic frogs and those that breed in permanent (lentic or lotic) water bodies (e.g. Litoria wilcoxii, L. rheocola, L. peronii, L. fallax, Limnodynastes peronii, Rheobatrachus spp.); (2) ephemeral water group, frogs that breed in temporary lentic water bodies (e.g. Litoria caerulea, L. gracilenta, most Uperoleia spp, Cyclorana spp.); and (3) terrestrial group, frogs that are not associated with water bodies, such as those with intracapsular or direct development (e.g. Assa darlingtoni and the microhylids, such as Cophixalus ornatus) (Tyler 1994, Cogger 2000). Some frog species typically breed in both permanent and ephemeral water bodies (e.g. Litoria rubella and $L$. inermis). If sampling these species, the type of water body that they are associated with should be recorded. Frog species associated with permanent water should be targeted initially, as these have been shown to be infected regularly with $B d$, followed by ephemeral water and terrestrial frogs (Berger et al. 2004, Speare et al. 2005, Kriger \& Hero 2007a).

For each bioregion, at least 2 species from each ecological group should be selected, and the required number of individuals from each species throughout the bioregion should be sampled ( $\mathrm{n}=60$, see 'Sample size'). Although a plan is useful, we recommend that surveyors be prepared to collect samples from species that are readily detectable and in sufficient numbers while in the field rather than to predetermine targeted species, especially for the ephemeral water group in more xeric habitats. This recommendation is made to maximise outcomes for survey effort because the majority of time and cost associated with the field component of surveys in Australia is expended on travelling to and from the survey site. In many regions of Australia there may only be 1 ecological group present. 
If insufficient animals are found then individuals from both or more species from the same group may be pooled. However, it is better to exclude negative samples from 1 or 2 individuals from a species, as they complicate the data without providing much information.

It is better to use the same species where possible throughout the distribution of the ecological group in all bioregions for consistency, targeting the 46 species currently known to be susceptible to infection with $B d$ (Speare \& Berger 2007). One must be sure that the species targeted are not resistant to infection with $B d$. For many species of amphibians, population, metapopulation or ecologically significant unit data are not available. For this survey, the population will be defined by the distribution of the species within a bioregion (see Cogger 2000 for a summary of indicative distributions of species and McDonald 2002 for comments).

Life stage: Knowledge of whether results from 1 life stage (e.g. tadpoles) can be extrapolated to another (e.g. adults) is needed for different species. Surveying tadpoles may be more sensitive than surveying frogs since in some species, the prevalence of $B d$ in tadpoles is higher than the prevalence in frogs; e.g. Mixophyes spp. in southeastern and northeastern Queensland, and Litoria ewingii in Tasmania (Berger et al. 1999, Woodhams \& Alford 2005, Obendorf \& Dalton 2006, Symonds et al. 2007, S. Cashins pers. comm.). Tadpoles may be a more convenient life stage to sample because they can be collected at any time of the day, unlike nocturnal adults, and they are present in water bodies for extended periods after breeding events when adults may be absent. Identification to species may not be possible, as many tadpoles remain undescribed. Only 1 reference identification book has been published, which is for tadpoles in southeastern Australia, with the remainder of descriptions scattered in the literature (Anstis 2002). Data on the relationship between prevalence of infection in tadpoles compared with frogs is required from a range of species with different breeding strategies, duration of tadpole stage and habitat types. Length of tadpole stage appears to be important, as higher prevalences have been observed in older tadpoles (Symonds et al. 2007). In some species in open forest and grasslands, such as Limnodynastes spp. and Litoria rubella, the tadpole stage may only last between 2 and 3 wk and infection may not progress sufficiently within that time to be readily detectable (Rachowicz \& Vredenburg 2004). Water temperatures in ephemeral pools in monsoon and arid Australia may reach above $40^{\circ} \mathrm{C}$ (Tyler 1994), which would prevent infection with $B d$. Tadpoles that over-winter may be more likely to be infected, as they may be exposed to water bodies contaminated with $B d$ for longer and at times when temperatures favour Bd (Symonds et al. 2007).
Therefore, we suggest swabbing tadpoles, as well as frogs, when possible. Where results from tadpoles can be confidently extrapolated to adults, then only tadpoles need to be tested if they are the easier life stage to sample. Testing tadpoles with grossly abnormal mouthparts is a higher priority, as this may increase the chance of obtaining positive results (Fellers et al. 2001, Rachowicz \& Vredenburg 2004, Obendorf \& Dalton 2006, Symonds et al. 2007). However, the association between mouthpart abnormalities in tadpoles and infection with $B d$ may not occur in all species (Felger et al. 2007, Padgett-Flohr \& Goble 2007). In addition, abnormalities may occur for other reasons, such as low temperatures (Rachowicz \& Vredenburg 2004).

Sample size: The necessary sample size is dependent on the minimum prevalence expected if the population were infected. The expected apparent prevalence of chytridiomycosis depends on the sensitivity of the diagnostic test. Using the TaqMan qPCR test (Boyle et al. 2004) the minimum apparent prevalence of $B d$ in infected Australian amphibian populations is $\geq 5 \%$ when conditions are optimal, such as when environmental maximum air temperatures are $<27^{\circ} \mathrm{C}$ (Speare et al. 2005, Kriger \& Hero 2007b, L. Skerratt et al. unpubl. data). This expected minimum apparent prevalence takes into account the sensitivity of the qPCR test, which in wild frogs in northern Queensland is approximately $75 \%$ (L. Skerratt et al. unpubl. data). Therefore one needs to randomly sample 59 individuals (round up to 60) to be $95 \%$ certain of detecting 1 positive frog when the apparent prevalence is $\geq 5 \%$ and when using a qPCR test with perfect specificity (the accuracy of the diagnostic qPCR test needs to validated in the diagnostic laboratory undertaking the testing before one can assume the above sensitivity and specificity) (DiGiacomo \& Koepsell 1986). A close approximation to the number of individuals that need to be tested to be $95 \%$ certain of detecting at least 1 positive frog is $\mathrm{n}=3 / p$ where $p$ is the prevalence expressed as a proportion (Hanley \& Lippman-Hand 1983).

Unfortunately, the qPCR test has not always been $100 \%$ specific in James Cook University's laboratory (L. Skerratt et al. unpubl. data). The reasons for this are speculative but appear to be most likely due to contamination either in the field or the laboratory (Rowley et al. 2007, L. Skerratt et al. unpubl. data). The risk of contamination can be reduced by good field hygiene protocols and laboratory methods. Where the qPCR test is less than $100 \%$ specific, a population should be regarded as positive if a qPCR result has been confirmed by a consistently high specific test, such as immunoperoxidase staining of a histological section (Berger et al. 2002, Hyatt et al. 2007). This was recently undertaken in Indonesia, where tadpoles with abnor- 
mal mouthparts were collected and preserved for histological testing during a swabbing survey of frogs and tadpoles (M. Kusrini et al. unpubl. data). Alternatively in this situation, probability methods can be used to determine the threshold number of positive test results that must be obtained from the number sampled before the disease is regarded as being present. This method relies on knowing the sensitivity and specificity of the test, the minimum expected true prevalence (minimum apparent prevalence is $5 \%$ in Australia), the probability of detecting disease at the minimum true prevalence (we suggest $95 \%$ to be reasonably confident in declaring a population free from disease), the probability of incorrectly concluding that disease is present when it is absent (we suggest $5 \%$ to reduce the likelihood of falsely declaring populations to be positive) and the population size (which one can assume is generally very large) (Thrusfield 2005). These are standard epidemiological methods used to prove freedom from disease (Cameron 1999). Even with a sensitivity and specificity both equal to $98 \%$, one would need to sample approximately 191 individuals and have 8 positives before declaring the population to have $B d$, given a minimum true prevalence of $5 \%$. Minimum true prevalence is in fact higher than this in infected Australian frogs given that minimum apparent prevalence is $5 \%$ and test sensitivity is approximately $75 \%$, and that specificity can vary between 94 and 100\% at James Cook University's laboratory and appears to be mostly dependent on field and laboratory procedures (L. Skerratt et al. unpubl. data). Using these probability methods will reduce the likelihood of false positives affecting the assessment of $B d$ distribution. It also highlights the importance of determining the sensitivity and specificity of the laboratory's qPCR test and the need for quality control of field hygiene methods and the diagnostic test to ensure $100 \%$ specificity of the testing procedure (see 'Diagnostic tests' section for further comments).

If a population is positive for chytridiomycosis, one may stop testing from that population (there is no need to test the remaining samples) and sympatric populations belonging to that same ecological group in the bioregion (they are also likely to be infected unless they are innately resistant).

We acknowledge that sampling is not random and that the nature of the spatial distribution of chytridiomycosis in frog populations is unknown. However, if we assume that $B d$ spreads throughout a population rather than forming discrete clusters of infection and we sample systematically throughout most of the distribution of a population, then the certainty of detecting at least 1 positive frog will closely approximate $95 \%$.

Surveying strategy: The spacing of sampling within populations will vary depending on distribution and accessibility of the population within the bioregion, and the size of the bioregion. It is important to sample as widely as possible for each population of interest within the bioregion. This should result in sampling from heterogeneous areas and provide a non-biased sample of the population. For example, if the population is spread over $100 \mathrm{~km}$ within the bioregion, then the aim should be to collect periodically over the $100 \mathrm{~km}$, i.e. collect 15 individuals every $25 \mathrm{~km}$ rather than collecting all tadpoles or frogs from the same location. We recommend sampling no more than 15 individuals of a species at a location, hence a minimum of 4 locations per population. Populations from different ecological groups may overlap; therefore, it will be possible to sample more than one ecological group concurrently.

Active males will be more readily observed and captured. There was no evidence of a difference in prevalence between males and females in Taudactylus eungellensis and Litoria jungguy/wilcoxii ( $\mathrm{n}=71$ ) (Retallick et al. 2004). In southeastern Queensland, Kriger \& Hero (2006) found male Litoria wilcoxii had a higher prevalence, while in northern Queensland, females and juveniles of L. rheocola, L. genimaculata and L. nannotis may have a higher prevalence (L. Skerratt et al. unpubl. data). As with many infectious diseases, the epidemiology of chytridiomycosis will vary with environment and host species.

It is important to test all sick frogs seen, as a previous study found that $>50 \%$ had chytridiomycosis (Berger et al. 2004). It is also recommended that any ill or recently dead frogs be retained as whole specimens for necropsy, with a toe clip stored in $70 \%$ ethanol and/or a swab taken for PCR and the body fixed in 10\% buffered neutral formalin or frozen at $-20^{\circ} \mathrm{C}$. Performing complete pathological examinations on all dead frogs is essential to detect diseases other than chytridiomycosis and to determine the cause of death.

Using this strategy the number of samples for Australia could be relatively small, given that the current predicted distribution of $B d$ in Australia is similar to the current known distribution (Retallick 2003, Speare et al. 2005). Further sampling is probably only required to confirm this. For example, if areas with low probability of having $B d$ continually test negative, then the current predictive model of the distribution of $B d$ is correct and only a proportion of these areas will need to be tested. In addition, for populations in infected regions the number of samples requiring testing will be greatly reduced if the prevalence of chytridiomycosis is high using the qPCR test (as testing will stop once there are positive samples) and if some groups are absent from bioregions. The number of samples will increase if several species within an ecological group within a bioregion need to be sampled, i.e. if the distribution of an 
ecological group within the bioregion is determined by several species due to the heterogeneity of the bioregion. The number will also increase as the accuracy of the chosen diagnostic test decreases.

Season: The appropriate season to sample frogs will vary throughout Australia and with habitat, elevation and frog species. Successful collection of the desired number of samples will depend on when frogs are detectable, such as after rainfall events or when temperatures are warmest; however, this may not be the optimal time for chytridiomycosis. Temperatures $\geq 27^{\circ} \mathrm{C}$ are known to be unfavourable for detecting chytridiomycosis (Longcore et al. 1999, Berger 2001, Woodhams et al. 2003, Berger et al. 2004, Piotrowski et al. 2004, McDonald et al. 2005, Kriger \& Hero 2007b). Deaths from chytridiomycosis have occurred experimentally from $27^{\circ} \mathrm{C}$ down to $12^{\circ} \mathrm{C}$ (Berger et al. 2004, Carey et al. 2006). This means, for example, that sampling in southern Queensland should be conducted in spring, when temperatures are similar to those favourable for chytridiomycosis and frogs are most detectable. However, rainfall is still required to activate some frogs during this time, e.g. Litoria chloris, $L$. dentata and burrowing frogs. In contrast, sampling in the monsoonal dry tropics of Australia must occur in summer, when ephemeral breeders are detectable. This type of sampling depends on rainfall events and accessibility to these inundated areas. Temperatures at these times may be suboptimal for detecting chytridiomycosis.

Diagnostic tests: The ideal diagnostic method for this survey is swabbing frogs for the qPCR test (Boyle et al. 2004, Hyatt et al. 2007), which is more sensitive than histology (Boyle et al. 2004, Kriger et al. 2006b, Hyatt et al. 2007, L. Skerratt et al. unpubl. data). However, false positives may occur when using qPCR tests if stringent hygiene protocols are not followed in the field or the laboratory undertaking the testing does not have adequate quality control to prevent contamination. A poor pipetting technique or procedure appears likely to lead to contamination (S. Garland et al. unpubl. data). Unless a field worker and laboratory can demonstrate that their testing is $100 \%$ specific, they must attempt to confirm positive results by another test where possible, especially when the result is very important. The disadvantage of other diagnostic tests like histology on toe clips, which are generally $100 \%$ specific, is that they may have low sensitivity-25\%, compared with qPCR at around $75 \%$ on frogs in the Wet Tropics of northern Queensland (Hyatt et al. 2007, L. Skerratt et al. unpubl. data). Alternatively, one must rely on probability methods and weigh up the cost of a potential false positive. Other diagnostic tests, such as alternative PCR tests, histology, immunostaining and examination of skin scrapings, can be useful for diag- nosis in different situations and may be more economical in certain situations (Berger et al. in press).

Studies indicate that the qPCR test appears to have $100 \%$ analytical specificity for $B d$ (Boyle et al. 2004, Hyatt et al. 2007). However, it is important to intermittently test this to make sure positive tests are actually due to $B d$ detection. This will require sequencing of the PCR product. Contamination of samples with $B d$ is the most likely cause of false positives and could occur during field collection or during laboratory testing. Adherence to hygiene protocols in the field, such as wearing new gloves/bags for each frog, will reduce contamination during collection (Speare et al. 2005). In the laboratory, negative controls will detect any systematic contamination, although they may not indicate whether infrequent contamination is occurring. The PCR test can be run in triplicate for each sample and all 3 tests must be positive before the swab is regarded as definitively positive if one wants to ensure high specificity. Whilst 1 or 2 of the 3 tests being positive may be an accurate result due to low levels of DNA in the sample or high levels of inhibition, it is more likely to be due to contamination than if all 3 wells were positive (L. Skerratt et al. unpubl. data). The animal should preferably be resampled or the test repeated if contamination of the sample can be ruled out (Hyatt et al. 2007). This will reduce the likelihood of infrequent contamination during the testing procedure leading to false positives (Boyle et al. 2004, Hyatt et al. 2007). In ecological studies these false positives may not warrant consideration if they occur at a low rate. One must also consider false negatives due to inhibition of the PCR by dirt on swabs or possibly secretions from frog skin (A. Hyatt pers. comm., L. Skerratt et al. unpubl. data). As an additional safeguard against false negatives, Hyatt et al. (2007) used an internal positive control of nucleic acid from a plasmid not known to occur in nature to detect inhibition of the PCR reaction. Data on the probability of inhibition of PCR when testing wild populations has not been published.

Batch testing would reduce costs. Preliminary trials indicate that up to 5 swabs from separate individuals may be combined, but there is loss of sensitivity when the amount of $B d$ in samples is low using the methods of Hyatt et al. (Hyatt et al. 2007, L. Skerratt et al. unpubl. data). In addition, a singlicate assay could be used as a screening test with the triplicate assay used in series to confirm any positives, which would reduce costs. Kriger et al. (2006a), in a theoretical analysis, had no significant loss in sensitivity in their survey of frogs in southeast Queensland. When testing in batches and there is a positive batch, individual samples could be tested to ensure at least 1 sample tests positive. To do this, each sample needs to be extracted separately and aliquots pooled for testing. 
This may reduce the likelihood of contamination biasing results.

Storing swabs at $23^{\circ} \mathrm{C}$ in the laboratory for at least 6 mo does not reduce sensitivity (Hyatt et al. 2007). However, temperatures higher than this may reduce the amount of DNA detected (Van Sluys et al. 2008). We recommend a prudent approach of storing swabs at $4^{\circ} \mathrm{C}$ or lower when possible, such as in a cooler on ice. If tests can not be done within 6 mo, freezing swabs is recommended. There is no loss of sensitivity of frozen swabs stored at $<-20^{\circ} \mathrm{C}$ for $1 \mathrm{yr}$ (Kriger et al. 2006b).

Most researchers in Australia use a specific swab for the qPCR (Medical Wire and Equipment, UK MW 100100) (Hyatt et al. 2007). To allow comparison across surveys using this swab and the qPCR test, a standard swabbing method has been proposed. Although swabbing methods have not been compared, a standard swabbing technique has been accepted that focuses on skin surfaces that have the most frequent and intense infections: ventral surfaces of the abdomen, thighs, and hands and feet are swabbed twice (i.e. 2 strokes of the swab) for surveying frog populations (Husbandry \& Hygiene Conference, 10-14 Dec 2004, Amphibian Research Centre, Werribee; Berger et al. 2005, Puschendorf \& Bolaños 2006). A standard method for swabbing mouth parts of tadpoles has not been suggested to date and may not be practical because of the diversity in mouthpart morphology, although methods could be standardised by type of mouthparts i.e. suctorial versus filter feeding (S. Cashins, pers. comm.). For sampling tadpole mouthparts 2 techniques have been described: (1) destructive sampling with excision of the mouthpart (Obendorf 2005, Knapp \& Morgan 2006, Obendorf \& Dalton 2006) and (2) non-destructive sampling by touching the tip of the swab against the tadpole mouthpart (Obendorf \& Dalton 2006) or by using wooden toothpicks (Retallick et al. 2006).

Other outcomes of the survey: The survey may result in additional information on habitat preferences, prevalence and seasonal occurrence of chytridiomycosis. However, these issues are more complex than mapping, requiring greater sample sizes, so precise data will not be obtained.

Survey protocol methodology. The researcher should conduct a survey for $B d$ as follows:

(1) Choose bioregions to sample initially based on priorities of threatened species, regions next to infected regions, ecological groups not sampled, and species not sampled in infected bioregions

(2) Determine which ecological groups and species are present within the bioregion

(3) Determine the distribution of species within the ecological groups present

(4) Choose species (at least 2), from each of the 3 ecological groups, to be sampled throughout the distribution of the ecological group within the bioregion (choose species that are easy to find, widely distributed and are likely to be infected with $B d$ )

(5) Select a time of year to sample those species based on maximising the likelihood of detecting both frogs and $B d$. It may be necessary to wait for rain for ephemeral water species

(6) Determine accessibility to the distribution of those species within the bioregion

(7) Sample systematically throughout accessible parts of the distribution for each species to be sampled within the bioregion. It may be necessary to divide the distribution of species within a bioregion into smaller areas if the bioregion is large and to prioritise sampling of areas based on likelihood of $B d$ infection. The recommended minimum area within a bioregion to be surveyed is $20 \%$ of accessible distribution of targeted species. Accessible areas may vary throughout the year, for example, access is lower in the peak of the monsoonal wet, when species are active, compared with the early and late monsoon

(8) Initially sample groups likely to be infected, such as permanent water species, followed by ephemeral water species if present

(9) Collect samples from at least 60 individual frogs from each species sampled. More frogs will need to be sampled from parts of the distribution where they are more abundant in order to ensure sampling fractions are consistent and that the sample is representative of the population

(10) Sample the mouthparts of 60 tadpoles from each species concurrently when sampling frogs, if possible, if the likelihood of infection of tadpoles is unknown. Alternatively, if likelihood of infection of tadpoles is known then they may be sampled instead of frogs if they are more convenient to sample and their infection status can be extrapolated to adults

(11) Take a GPS reading at each collection point. A collection point is defined by a $1 \mathrm{~km}$ radius, and a maximum of 15 individuals should be collected from each collection point. Space collection points evenly throughout the bioregion to be surveyed for target species. This may not be possible if the species and preferred habitat is not distributed evenly across the landscape and environmental conditions vary within the collection period, e.g. rainfall event

(12) Combine sampling of species from different ecological groups where possible

(13) Test the 60 samples until at least 1 positive is found, given perfect specificity or, alternatively, test the number of samples until 1 more than the threshold number of positives are detected, given an imperfect specificity. Use software such as Freecalc (AusVet) to calculate the number of samples and threshold number of positives needed. The remaining samples may be tested if additional information on the distribution of $B d$ within a bioregion is needed 


\section{DISCUSSION}

Using these protocols the approximate number of samples needed to survey for chytridiomycosis in Australian frog populations could be relatively small. Not all samples will need to be analysed, given that once enough positives are detected, the remaining samples from the positive population will not be tested. Groups in some bioregions will not need to be surveyed if sympatric populations of species at higher risk of infection with $B d$ are negative or the group does not occur. Results already exist for some bioregions, e.g. the Wet Tropics and Southeast Queensland bioregions (Speare et al. 2005). The cost of sample collection includes salary, vehicle, field equipment and consumable costs. This approximates AU $\$ 20$ per sample in bioregions close to population centres, such as the Wet Tropics, where frog numbers are higher and found over a smaller distance. Field collection costs will rise sharply in remote areas, such as the Gibson Desert, Fink or Cape York bioregions - although climatic modelling suggests that large parts of these regions are unlikely to support $B d$ and therefore are of low priority for surveying (Retallick 2003, R. Puschendorf et al. unpubl. data). Laboratory costs for testing samples, including reagent and labour costs, are a minimum of approximately AU\$25 per sample using the qPCR. This does not include overhead and equipment costs and the cost of expertise to manage and interpret the qPCR (Speare et al. 2005).

This protocol should be continually adjusted to account for new findings as knowledge about chytridiomycosis is rapidly increasing. As crucial information on the distribution of chytridiomycosis is lacking in some species and groups, we recommend more detailed targeted surveying in the first year of implementation of this protocol, then reassessing the protocol to increase its efficiency.

We recommend that the current Australian national database on distribution of $B d$ (Speare et al. 2005) be upgraded and that the mapping protocol be disseminated to interested parties, such as conservation land managers and frog groups. The Australian Wildlife Health Network could maintain this national database and provide updates on distribution on its web site. It could also regularly update a predictive model of the distribution of $B d$ to direct future surveys. It is important to fund all aspects of this work, including surveys, competent diagnostic facilities, database management, data analysis and interpretation, and information dissemination.

We have provided a template for other countries and international bodies, such as the World Organisation for Animal Health (OIE), to map the distribution of $B d$ and determine areas where the fungus could spread.
This will inform countries of the risk of introduction and exportation of $B d$ and its likely impact on their native frog fauna. Appropriate preventive measures, such as quarantine and testing of imported frogs and their products, such as fresh legs, can be undertaken to prevent introduction (AGDEH 2006). This single action may have the greatest impact on global frog conservation because the spread of $B d$ is driving frog extinctions (Skerratt et al. 2007). Our protocol will also enable conservation actions to be directed towards populations most likely to be affected by chytridiomycosis.

Acknowledgements. The preparation of this protocol was funded and initiated by the Australian Government Department of the Environment and Heritage (tender 63/2003). We thank K. Kriger, R. Müller, R. Alford, A. Phillott, A. Hyatt, J.-M. Hero, S. Cashins and K. Murray for helpful discussions and comments on the manuscript.

\section{LITERATURE CITED}

Anstis M (2002) Tadpoles of South Eastern Australia: a guide with keys. Reed New Holland, Sydney

Australian Government Department of the Environment and Heritage (2006) Background document for the threat abatement plan: infection of amphibians with chytrid fungus resulting in chytridiomycosis. Department of Environment and Heritage, Canberra. Available at: www.deh. gov.au/biodiversity/threatened/publications/tap/chytrid/ pubs/chytrid-background.pdf

Berger L (2001) Diseases in Australian frogs. PhD thesis, James Cook University, Townsville

- Berger L, Speare R, Daszak P, Green DE and others (1998) Chytridiomycosis causes amphibian mortality associated with population declines in the rain forests of Australia and Central America. Proc Natl Acad Sci USA 95: 9031-9036

Berger L, Speare R, Hyatt A (1999) Chytrid fungi and amphibian declines: overview, implications and future directions. In: Campbell A (ed) Declines and disappearances of Australian frogs. Environment Australia, Canberra, p 23-33

Berger L, Hyatt AD, Olsen V, Hengstberger SG and others (2002) Production of polyclonal antibodies to Batrachochytrium dendrobatidis and their use in an immunoperoxidase test for chytridiomycosis in amphibians. Dis Aquat Org 48:213-220

Berger L, Speare R, Hines H, Marantelli G and others (2004) Effect of season and temperature on mortality in amphibians due to chytridiomycosis. Aust Vet J 82:31-36

Berger L, Speare R, Skerratt L (2005) Distribution of Batrachochytrium dendrobatidis and pathology in the skin of green tree frogs Litoria caerulea with severe chytridiomycosis. Dis Aquat Org 68:65-70

Berger L, Longcore JE, Speare R, Hyatt A, Skerratt L (in press) Fungal diseases of amphibians. In: Heatwole $\mathrm{H}_{\text {, }}$ Wilkinson J (eds) Amphibian biology: conservation and decline. Surrey Beatty and Sons, Chipping Norton

- Boyle DG, Boyle DB, Olsen V, Morgan JAT, Hyatt AD (2004) Rapid quantitative detection of chytridiomycosis (Batrachochytrium dendrobatidis) in amphibian samples using real-time Taqman PCR assay. Dis Aquat Org 60:141-148 
Cameron AR (1999) Survey toolbox for livestock diseases - a practical manual and software package for active surveillance in developing countries. Australian Centre for International Agricultural Research, Canberra

Carey C, Bruzgul JE, Livo LJ, Walling ML and others (2006) Experimental exposures of boreal toads (Bufo boreas) to a pathogenic chytrid fungus (Batrachochytrium dendrobatidis). EcoHealth 3:5-21

CIA (2007) Australia. The world fact book. Available at: https://www.cia.gov/library/publications/the-worldfactbook/geos/as.html

Cogger HG (2000) Reptiles and amphibians of Australia. Reed New Holland, Sydney

Department of the Environment, Water, Heritage and the Arts 2008). IBRA Version 6.1. Available at: www.environment. gov.au/parks/nrs/science/bioregion-framework/ibra/index. html (accessed 17 June 2008)

DiGiacomo RF, Koepsell TD (1986) Sampling for detection of infection or disease in animal populations. J Am Vet Med Assoc 189:22-23

Felger J, Enssle J, Mendez D, Speare R (2007) Chytridiomycosis in El Salvador. Salamandra 43:122-127

> Fellers GM, Green DE, Longcore JE (2001) Oral chytridiomycosis in the mountain yellow-legged frog (Rana muscosa). Copeia 945-953

Garner TWJ, Walker S, Bosch J, Hyatt AD, Cunningham AA, Fisher MC (2005) Chytrid fungus in Europe. Emerg Infect Dis 11:1639-1641

> Hanley JA, Lippman-Hand A (1983) If nothing goes wrong, is everything all right? JAMA 249:1743-1745

Hyatt A, Boyle D, Olsen V, Boyle D and others (2007) Diagnostic assays and sampling protocols for the detection of Batrachochytrium dendrobatidis. Dis Aquat Org 73: 175-192

Johnson M, Speare R (2003) Survival of Batrachochytrium dendrobatidis in water: quarantine and control implications. Emerg Infect Dis 9:922-925

Johnson M, Berger L, Philips L, Speare R (2003) Fungicidal effects of chemical disinfectants, UV light, desiccation and heat on the amphibian chytrid Batrachochytrium dendrobatidis. Dis Aquat Org 57:255-260

Knapp RA, Morgan JAT (2006) Tadpole mouthpart depigmentation as an accurate indicator of chytridiomycosis, an emerging disease of amphibians. Copeia 188-197

Kriger KM, Hero JM (2006) Cophixalus ornatus (ornate nursery frog). Chytridiomycosis. Herpetol Rev 37:443

Kriger KM, Hero JM (2007a) The chytrid fungus Batrachochytrium dendrobatidis is non-randomly distributed across amphibian breeding habitats. Divers Distrib 13: 781-788

Kriger KM, Hero JM (2007b) Large scale seasonal variation in the prevalence and severity of chytridiomycosis. J Zool (Lond) 271:352-359

Kriger KM, Hero JM, Ashton KJ (2006a) Cost efficiency in the detection of chytridiomycosis using PCR assay. Dis Aquat Org 71:149-154

Kriger KM, Hines HB, Hyatt AD, Boyle DG, Hero JM (2006b) Techniques for detecting chytridiomycosis in wild frogs: comparing histology with real-time Taqman PCR. Dis Aquat Org 71:141-148

Kriger KM, Pereoglou F, Hero JM (2007) Latitudinal variation in the prevalence and intensity of chytrid (Batrachochytrium dendrobatidis) infection in eastern Australia. Conserv Biol 21:1280-1290

Laurance WF, McDonald KR, Speare R (1996) Epidemic disease and the catastrophic decline of Australian rain forest frogs. Conserv Biol 10:406-413
Lips KR, Brem F, Brenes R, Reeve JD and others (2006) Emerging infectious disease and the loss of biodiversity in a neotropical amphibian community. Proc Natl Acad Sci USA 103:3165-3170

Longcore JE, Pessier AP, Nichols DK (1999) Batrachochytrium dendrobatidis gen. et sp. nov., a chytrid pathogenic to amphibians. Mycologia 91:219-227

McDonald KR (2002) Frog futures: Conservation issues and prospects for Queensland. In: Nattrass AEO (ed) Frogs in the Community: Proceedings of the Brisbane Symposium 13-14 February 1999. Queensland Frog Society, Brisbane

McDonald KR, Méndez D, Müller R, Freeman AB, Speare R (2005) Decline in the prevalence of chytridiomycosis in upland frog populations in North Queensland, Australia. Pac Conserv Biol 11:114-120

Obendorf D (2005) Developing field and diagnostic methods to survey for chytridiomycosis in Tasmanian frogs. Report prepared on behalf of the Central North Field Naturalists, for Department of Environment and Heritage, Canberra. Available at: www.deh.gov.au/biodiversity/invasive/ publications/tasmanian-frogs/index.html\#download

Obendorf D, Dalton A (2006) A survey for the presence of the amphibian chytrid fungus (Batrachochytrium dendrobatidis) in Tasmania. Pap Proc R Soc Tasman 140:25-29

OIE Aquatic Animal Health Standards Commission (2006) March report of the meeting of the OIE Aquatic Animal Health Standards Commission. Office Internationale des Epizooties, Paris

Olson D, Ronnenberg K (2008) Batrachochytrium dendrobatidis mapping project. Available at: www.parcplace.org/ bdmap2008update.html (accessed 6 February 2008)

Ouellet M, Mikaelian I, Pauli BD, Rodrigue J, Green DM (2005) Historical evidence of widespread chytrid infection in North American amphibian populations. Conserv Biol 19:1431-1440

Padgett-Flohr GE, Goble ME (2007) Evaluation of tadpole mouthpart depigmentation as a diagnostic test for infection by Batrachochytrium dendrobatidis for four California anurans. J Wildl Dis 43:690-699

Piotrowski JS, Annis SL, Longcore JF (2004) Physiology of Batrachochytrium dendrobatidis, a chytrid pathogen of amphibians. Mycologia 96:9-15

Puschendorf R, Bolaños F (2006) Detection of Batrachochytrium dendrobatidis in Eleutherodactylus fitzingeri: effects of skin sample location and histologic stain. J Wildl Dis 42:301-306

Rachowicz LJ, Vredenburg VT (2004) Transmission of Batrachochytrium dendrobatidis within and between amphibian life stages. Dis Aquat Org 61:75-83

Retallick RWR (2003) Bioclimatic investigations into the potential distribution of Batrachochytrium dendrobatidis in Australia. Department of Zoology and Entomology, University of Queensland, Brisbane, and School of Public Health, Tropical Medicine and Rehabilitation Sciences, James Cook University, Townsville

> Retallick RWR, McCallum H, Speare R (2004) Endemic infection of the amphibian chytrid fungus in a frog community post-decline. PLoS Biol 2:e351

> Retallick RWR, Miera V, Richards KL, Field KJ, Collins JP (2006) A non-lethal technique for detecting the chytrid fungus Batrachochytrium dendrobatidis on tadpoles. Dis Aquat Org 72:77-85

Ron SR (2005) Predicting the distribution of the amphibian pathogen Batrachochytrium dendrobatidis in the New World. Biotropica 37:209-221

Rowley JJL, Hemingway VA, Alford RA, Waycott M, Skerratt LF, Campbell R, Webb R (2007) Experimental infection and re- 
peat survey data indicate amphibian chytrid Batrachochytrium dendrobatidis may not occur on freshwater crustaceans in northern Queensland, Australia. EcoHealth 4:31-36

Skerratt LF, Berger L, Speare R, Cashins S and others (2007) Spread of chytridiomycosis has caused the rapid global decline and extinction of frogs. EcoHealth 4:125-134

Speare R, Berger L (2007) Global distribution of chytridiomycosis in amphibians. Amphibian Disease Home Page. Available at: www.jcu.edu.au/school/phtm/PHTM/frogs/ chyglob.htm

Speare R, Skerratt L, Berger L, Hines H and others (2005) A project that designs and trials a pilot survey to map the distribution of chytridiomycosis (caused by the amphibian chytrid) in Australian frogs. Final report for Project ID 44381 (tender 63/2003) to the Australian Government Department of Environment and Heritage. Available at: www.deh.gov.au/biodiversity/invasive/publications/ c-disease/distribution-survey.html

Symonds EP, Hines HB, Bird PS, Morton JM, Mills PC (2007) Surveillance for Batrachochytrium dendrobatidis using

Editorial responsibility: Alex Hyatt, Geelong, Victoria, Australia
Mixophyes (Anura: Myobatrachidae) larvae. J Wildl Dis 43:48-60

Thrusfield M (2005) Veterinary epidemiology, 3rd edn. Blackwell Science, Carlton

Tyler MJ (1994) Australian frogs. A natural history. Reed Books, Chatswood

Van Sluys M, Kriger KM, Phillott AD, Campbell R, Skerratt LF, Hero JM (2008) Storage of samples at high temperatures reduces the amount of amphibian chytrid fungus Batrachochytrium dendrobatidis DNA detectable by PCR assay. Dis Aquat Org (in press)

Weldon C, du Preez LH, Hyatt AD, Muller R, Speare R (2004) Origin of the amphibian chytrid fungus. Emerg Infect Dis 10:2100-2105

Woodhams DC, Alford RA (2005) Ecology of chytridiomycosis in rainforest stream frog assemblages of tropical Queensland. Conserv Biol 19:1449-1459

> Woodhams DC, Alford RA, Marantelli G (2003) Emerging disease of amphibians cured by elevated body temperature. Dis Aquat Org 55:65-67

Submitted: October 9, 2007; Accepted: April 14, 2008

Proofs received from author(s): June 18, 2008 